\title{
Influence of Varying Welding Current on Impact Strength of Metal Inert Gas Welding Joints
}

\author{
Vishvesh Dixit ${ }^{1}$, Yashwant Thakur ${ }^{2}$, Abhishek Gaurav ${ }^{3}$, Ishbir Singh ${ }^{4}$, Vijender \\ Rajora $^{5}$ \\ 1,2,3,4,5 (Department of Mechanical Engineering, School of Engineering \& Emerging Technologies,Baddi \\ University of Emerging Sciences and Technology, Baddi, H.P, India)
}

\begin{abstract}
MIG welding is one of the most commonly used welding process. Its productivity and quality depends upon many factors like arc voltage, current, weld speed and heat generated during welding. There have been many researches done on the MIG welding. In this particular study, an attempt has been made to investigate the effect of varying welding current with constant voltage on the impact strength of the weld bead of similar and different material. The objective of this is to design a $V$ - joint and check the strength of the similar and dissimilar metal pieces on different current and constant voltage conditions. The materials used in this study are mild steel and stainless steel. The method used for the impact testing is IZOD test.
\end{abstract}

Keywords: MIG welding, varying current, impact strength, Mild Steel (MS), Stainless Steel (SS).

\section{INTRODUCTION}

Metal inert gas welding is one of the most economical and efficient way to join two or more metals permanently and make them act as a single piece. MIG welding is also recognized by gas metal arc welding. It is a semi-automatic process by which an arc is produced due to which a feed wire is melted and the molten metal is used to join the metal plates. This process is done in the presence of an inert gas atmospheric contamination. This process is also refers as metal active gas welding (MAG welding) and it is a welding process in which an electric arc forms in between a consumable wire electrode and a work piece metal which heats the work piece metal(s) or the electrode which leads to melt and forms a weld causing them to join with each other [1][2].

There are many variables which affect the welding process like welding speed, welding voltage, welding current, heat generation and gas flow rate etc. The parametric conditions for this particular work has been choosen after detailed literature survey. The literature deals with the different parameters, material and experimental procedures [3][4][5][6]. In this particular study, the experiment was done by keeping the welding voltage constant and varying the welding current [7][8][9][10]. Welded metal pieces are then tested by using IZOD test for their impact strength. Similar and dissimilar metal pieces are joined using MIG welding to find their impact strength. The welded metals are as follows:

- $\quad$ Mild Steel - Mild Steel

- Stainless Steel - Stainless Steel

- $\quad$ Mild Steel - Stainless Steel.

\section{MATERIAL AND METHOD}

MIG welding is a widely used process for joining similar and dissimilar metal with each other. In this study two materials are welded using MIG welding heaving varying current and the constant voltage as the parameters.for this experiment two different materials are selected and then joined using MIG welding.

\subsection{MATERIAL}

There are different grades of steel which are used for the manufacturing and industrial purpose. Out of those different grades of steel two materials are selected for this particular experimental study. The selection of the material is on the basis of the availability and the industrial applications [11][12][13][14]. The two materials selected for the experiment areas follow.

Mild Steel: Mild steel is low magnesium steel containing about .30\% carbon in it. It has limited weld ability and low strength. Mild steel is used extensively in machinery and tool [15][16][17]. Selection of these steel are on the bases of their high wear resistance it is also called medium carbon steel or AISI 1030.

Stainless Steel: In this research type AISI 410 is used. Type 410 stainless steel is the basic alloy in martensitic family. It is an iron-chromium alloy contains $11.5 \%$ to $13 \%$ chromium and can be hardened by heat 
treatment to the highest strength level [18][19][20]. This type of steel finds major application in products that must resist atmospheric oxidation, mildly corrosive chemicals and wet and dry corrosion environment found in steam and gas turbine parts, bearing and cutlery. The chemical properties and mechanical properties of both the metals are given in the TABLE I and TABLE II.

TABLE I. Chemical Composition

\begin{tabular}{|c|c|c|c|c|c|c|}
\hline $\begin{array}{c}\text { Composition } \\
(\%)\end{array}$ & C & Mn & Si & Cr & P & S \\
\cline { 1 - 4 } type & & & & & & \\
\hline AISI 410 & 0.15 & 1.00 & 1.00 & $11.5-13.0$ & 0.04 & 0.03 \\
\hline AISI 1030 & $0.28-0.34$ & $0.60-0.90$ & 0.137 & - & 0.04 MAX & 0.05 MAX \\
\hline
\end{tabular}

TABLE II. Mechanical Properties

\begin{tabular}{|c|c|c|c|c|c|c|c|c|}
\hline Property & $\begin{array}{c}\text { Density } \\
\mathrm{Kg} / \mathrm{m}^{3}\end{array}$ & $\begin{array}{c}\text { Poisson } \\
\text { ratio }\end{array}$ & $\begin{array}{c}\begin{array}{c}\text { Elastic } \\
\text { modulus }\end{array} \\
\text { GPa }\end{array}$ & $\begin{array}{c}\text { Tensile } \\
\text { strength } \\
\text { GPa }\end{array}$ & $\begin{array}{c}\text { Elongation } \\
\%\end{array}$ & $\begin{array}{c}\text { Yield } \\
\text { strength } \\
\text { MPa }\end{array}$ & $\begin{array}{c}\text { Reduction } \\
\text { in area } \\
\%\end{array}$ & $\begin{array}{l}\text { Hard } \\
\text {-ness } \\
\text { BHN }\end{array}$ \\
\hline AISI 410 & 7800 & $0.27-0.30$ & 200 & 485 & 20 & 275 & 45 & 95 \\
\hline $\begin{array}{l}\text { AISI } \\
1030\end{array}$ & $7700-8030$ & $0.27-0.30$ & $190-210$ & 463.7 & 31.2 & 341.3 & 57.9 & 126 \\
\hline
\end{tabular}

\subsection{METHOD}

In this experimental study material used, AISI 410 and AISI 1030 commonly known as stainless steel and mild steel respectively, were selected as the base metal for experimentation. Both of their chemical and mechanical properties are shown in TABLE I. and TABLE II. The metal pieces were machined into $64 \mathrm{x} 12.7 \mathrm{x}$ $3.2 \mathrm{~mm}$ as per the ASTM standards. The surfaces of the pieces were grind to remove the dust and the other foreign particles. By machining the pieces a v-grooves were made on each of them and then the welding process is performed. Similar and dissimilar metal are joined to obtain the test specimens.

The diameter of the wire always depends upon the thickness of the metal plates to be welded. By identifying the welding parameters from literature survay the welding was performed. The effect of process parameter like varying current, gas flow rate and welding speed were then investigated. A standard ASTM specimen heving a v-notch of $2 \mathrm{~mm}$ is first fabricated by machining process. And by means of the IZOD test the impact strength of the welding specimens are found.

\section{RESULTS \& DISCUSSION}

In this paper, mild steel (AISI 1030) and stainless steel (AISI 410) were welded using MIG welding. By identifying the parameters and their ranges. The welding current was varying from $120 \mathrm{~A}$ to $160 \mathrm{~A}$ while the welding voltage remain constant.

The welding process is done on the similar and dissimilar metals and the welded metal plate specimen catagories obtain are as follows:

- $\quad$ mild steel - mild steel,

- $\quad$ stainless steel - stain steel,

- $\quad$ mild steel - stainless steel. 
In this experiment three sets of specimen were obtained on which IZOD test was performed . There are total nine welded plate specimens were obtained on which IZOD test was performed. The result obtained are shown in TABLE III.

TABLE III. Readings of izod test

\begin{tabular}{|c|c|c|c|c|c|}
\hline $\begin{array}{c}\text { Sr. } \\
\text { No }\end{array}$ & Material & $\begin{array}{c}\text { Current } \\
\text { (Ampere) }\end{array}$ & $\begin{array}{c}\text { Total } \\
\text { energy E1 } \\
\text { (Joule) }\end{array}$ & $\begin{array}{c}\text { Absorbed } \\
\text { energy } \\
\text { (E2) }\end{array}$ & $\begin{array}{c}\text { Remaining } \\
\text { Energy } \\
\text { (E1-E2) }\end{array}$ \\
\hline 1. & M.S.-M.S & 120 & 164 & 9 & 155 \\
\hline 2. & S.S.-S.S. & 120 & 164 & 11.2 & 152.8 \\
\hline 3. & M.S.-S.S & 120 & 164 & 50 & 114 \\
\hline 4. & M.S.-M.S. & 140 & 164 & 20 & 144 \\
\hline 5. & S.S.-S.S. & 140 & 164 & 8 & 156 \\
\hline 6. & M.S.-S.S. & 140 & 164 & 9 & 155 \\
\hline 7. & M.S.-M.S. & 160 & 164 & 18 & 146 \\
\hline 8. & S.S.-S.S. & 160 & 164 & 30 & 134 \\
\hline 9. & M.S.-S.S. & 160 & 164 & 16 & 148 \\
\hline
\end{tabular}

Using the data provided in the TABLE III three graphs were plotted for each type of specimen category. The remaining energy v/s welding current graph were plotted in which the Y-axis represents the remaining energy, whereas the $\mathrm{X}$-axis represents the welding current applied during the welding process respectively.

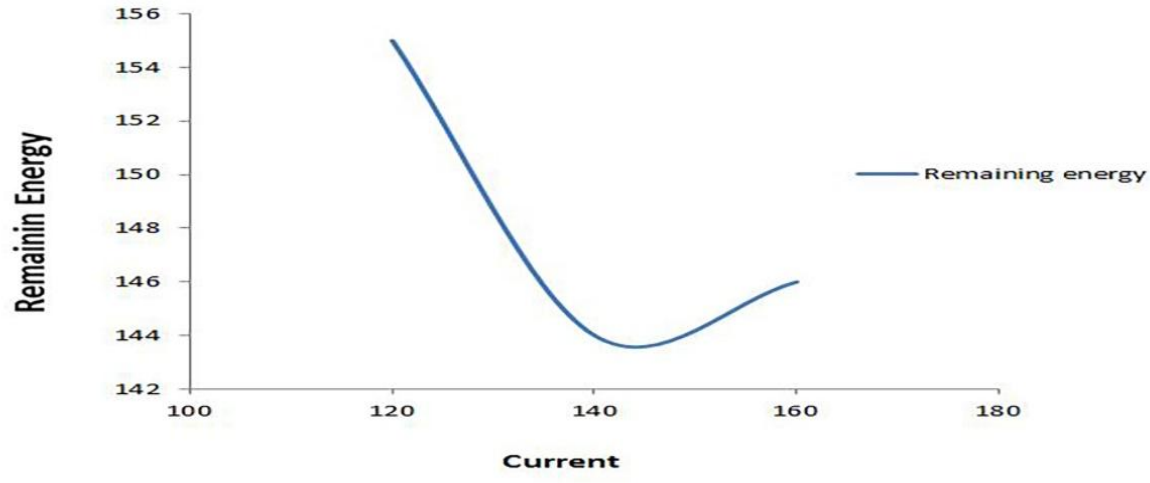

Fig. 1: Current vs Remaining energy for MS-MS

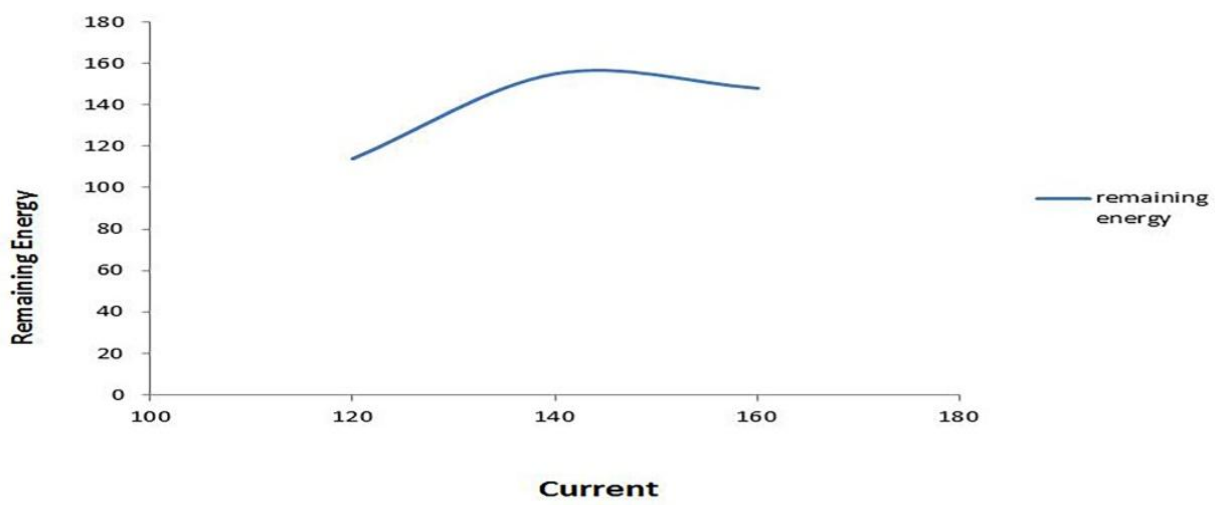

Fig. 2: Current vs Remaining energy for MS-SS 


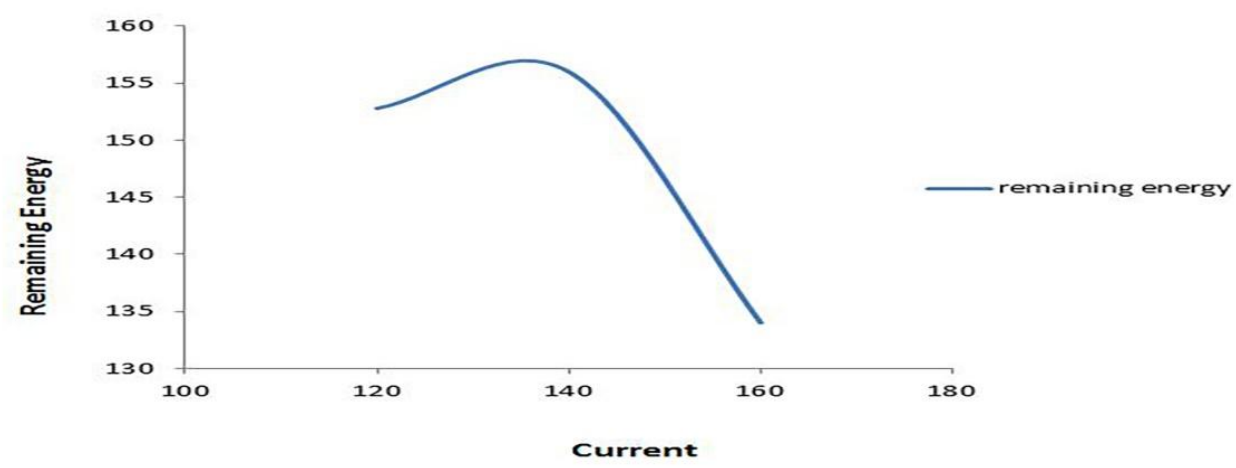

Fig. 3: Current vs Remaining energy for SS-SS

In mild steel - mild steel graph the range of the current was taken form 120 amp to 160 amp. In this graph the remaining energy of the material starts decreasing as the value of the current get increased from 120 amp to $140 \mathrm{amp}$, but when the input current was increased further from $140 \mathrm{amp}$ to $160 \mathrm{amp}$ there was a slight increase in the value of remaining energy. The slope of the increase in remaining energy was small as compare to the slope of the decrease in the value of remaining energy. The data related to MS-MS welding has been represented in Figure 1.

In case of stainless steel - stainless steel welding graph, the value of the current is in the range between $120 \mathrm{amp}$ to $160 \mathrm{amp}$. The value obtained for the remaining energy get increased as the value of the current get increased from $120 \mathrm{amp}$ to $140 \mathrm{amp}$. On further increase in the input value of current upto $160 \mathrm{amp}$, the value of the remaining energy started decreasing. The graph of stainless SS-SS steel has been represented in Figure 3.

In case of mild steel - stainless steel, the current papameter also ranges from $120 \mathrm{amp}$ to $160 \mathrm{amp}$. In this graph the value of remaining energy increased as the input value of current is increased from 120 to 140 amp and starts decreasing with further increase in the value of current range from 140 to 160 amp. Both the slopes of increase in the remaining energy and decrease in the remaining values are less when compaired with the mild steel-mild steel graph and ss-ss graph. The graph of MS-SS has been shown in Figure 2.

\section{CONCLUSION}

The process parameters such as welding current, wire diameter, welding voltage and gas flow rate are first studied. On the basis of literature, the parametric ranges are selected. i.e. 120 to 160 Amp. In this present study the metal selected was MS and SS and joined by using a MIG welding process. Similar metal and dissimilar metals are joined to perform the experiment. The readings were obtained by performing IZOD test for each specimen. It is to be concluded form this experimental study thatamong three different catagories of material joints i.e. MS-MS, SS-SS and MS-SS joint, the highest strength of the joint was obtain by the SS-SS joint at 140 Amp, whereas the lowest remaining energy was obtain by the MS-SS joint at 120 Amp.

[1] Klas Weman, Welding Processes Handbook., CRC Press, 2003.

\section{REFERENCES}

[2] W. R. Oates and A. M. Saitta, WELDING HANDBOOK, American Welding Society, vol. 4, no. eighth edition.

[3] P. Taylor, A. Saldanha, D. B. Fernandes, and C. A. Mendes, Methodology for determination of parameters for welding MIG with variable polarity, Welding International., vol. 23, no. April 2015, 37-41, 2008.

[4] R. H. G. e Silva, J. C. Dutra, and R. Gohr, Scientific and technological fundamentals for the development of the controlled short circuiting MIG/MAG welding process (CCC)-A literature review. Part 1 of 3: History and wire-electrode melting aspects, Welding International, vol. 22, no. 12, 847-852, 2008.

[5] K. B. Pipavat, D. Pandya, and V. Patel, Optimization of MIG welding P rocess Parameter using Taguchi Techniques, International Journal of Advanced Engineering and Research development, vol. 1, no. 5, 2014.

[6] Rogério dos Santos Alves, Alex Soares de Souza et. al., Welding Handbook, Igarss 2014, no. 1, 1-5, 2014.

[7] Alves de Resende, V. A. Ferraresi, A. Scotti, and J. C. Dutra, Influence of welding current in plasma-MIG weld process on the bead weld geometry and wire fusion rate, Welding International, vol. 25, no. 12, 910-916, 2011.

[8] Y. Hosoi, Introduction to stainless steel, Journal of Japan Institute of Light Metal, vol. 37, no. 9, 624-635, 1987.

[9] V.Ariance, MIG Welding parametric optimization using taguchi's orthogonal array and analysis of variance, International Journal of Research Review In Eengineering Science \& echnology, vol. 40504, no. 859, 211-217, 2004. 
[10] C. L. Jenney and A. O’Brien, Welding handbook, American Welding Society, vol. 1, 982, 1991.

[11] S. Tathgir, A. Bhattacharya, and T. K. Bera, Influence of Current and Shielding Gas in $\mathrm{TiO}_{2}$ Flux Activated TIG Welding on Different Graded Steels, Materials and Manufacturing Processes, vol. 30, no. May 2015, 1115-1123, 2015.

[12] AD. and S. S. Ajit Hooda, Optimization of Mig Welding Process Parameters To Predict Maximum Yield Strength in Aisi 1040, International Journal of Mechanical Engineering and Robotic Research, vol. 1, no. 3, 13, 2012.

[13] N. Pawan Kumar, Dr B.K. Roy, Parameters Optimization for Gas Metal Arc Welding of Austenitic Stainless Steel ( AISI 304 ) \& Low Carbon Steel using Taguchi's Technique, International Journal of Engineering and Management Research, no. 4, 18-22, 2013.

[14] E. K. Hirata, L. F. Beltzac, P. C. Okimoto, and A. Scotti, Influence of current on the gross fusion efficiency in MIG/MAG welding, Welding International, vol. 30, no. 7, 504-511, 2016.

[15] T. Kurşun, Effect of the Gmaw and the GMAW-P Welding Processes on Microstructure, Hardness, Tensile and Impact Strength of Aisi 1030 Steel Joints Fabricated by ASP316L Austenitic Stainless Steel Filler Metal, Archives of Metallurgy and Materials, vol. 56, no. 4, 2011.

[16] S. R. Patil and C. A. Waghmare, Optimization of Mig Welding Parameters for Improving Strength of Welded Joints, International Journal of Advanced Engineering Research and Studies, vol. II, no. July-Sept., 14-16, 2013.

[17] S. Utkarsh, P. Neel, M. T. Mahajan, P. Jignesh, and R. B. Prajapati, Experimental Investigation of MIG Welding for ST-37 Using Design of Experiment, International Journal of Scientific and Research Publications, vol. 4, no. 5, 1-4, 2014.

[18] S. D. Ambekar and S. R. Wadhokar, Parametric Optimization of Gas Metal Arc Welding Process by using Taguchi Method on stainless steel AISI 410, International Journal of Research in Modern Engineering and Emerging Technology, vol. 3, no. 1, 1-9, 2015.

[19] L. Mariano, S. Francisco, and R. Perito, Martensitic Stainless Steels Low-temperature Nitriding: Dependence of Substrate Composition 2 . Experimental Procedure, Materials Research, vol. 18, no. 3, 622-627, 2015.

[20] M. S. F. De Lima and A. M. D. E. Santo, Phase transformations in an AISI 410S stainless steel observed in directional and laserinduced cooling regimes, Materials Research, vol. 15, no. 1, 32-40, 2012. 